\title{
Effect of Preparation Technique on Endobronchial Ultrasound-Guided Transbronchial Needle Aspiration Sample Adequacy: 3 Years of Experience from a Single Center
}

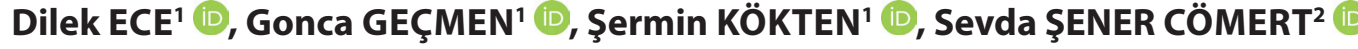 \\ Department of ${ }^{1}$ Pathology, ${ }^{2}$ Chest Disease, Dr. Lütfi Kirdar Kartal Training and Research Hospital, ISTANBUL, TURKEY
}

\begin{abstract}
Objective: Endobronchial ultrasound-guided transbronchial needle aspiration (EBUS-TBNA) is increasingly used to sample mediastinal lymph nodes and lesions. However, the methodological details of an optimal preparation technique for aspirated material have not yet been clearly determined. This study was an evaluation of the effect of 2 preparation techniques on the adequacy of aspirated specimens.

Material and Method: A retrospective analysis was performed of EBUS-TBNA samples obtained at the institution over a total of 36 months. Two periods were examined. Almost all of the aspirated material was smeared onto slides and fixed with $95 \%$ alcohol in the first period of the study. Subsequently, to improve diagnostic ability, a pair of slides was prepared from each needle pass: the first was air-dried, and the second was fixed in 95\% alcohol. The remainder of the aspirate was kept for cell block analysis.

Results: In total, 462 samples were obtained from 260 patients. The overall sampling adequacy was $74 \%$ in the first and $81.1 \%$ in the second period $(\mathrm{p}<0.05)$. Approximately $14 \%$ of the specimens included a sufficient number of cells for immunohistochemical cell block evaluation in the first period and $42 \%$ in the second period $(\mathrm{p}<0.001)$. Histological subtyping of non-small cell lung carcinoma was determined in $18(56.3 \%)$ and the primary origin of a tumor was determined based on morphological and immunohistochemical properties in 32 (84.2\%) of the patients in the first and second periods, respectively.
\end{abstract}

Conclusion: The access to a sufficient EBUS-TBNA sample and the ability to perform the appropriate preparation can impact the specific diagnosis and treatment of patient with a single procedure.

Key Words: Adequacy, Endobronchial ultrasound, Preparation technique, Transbronchial aspiration

\section{INTRODUCTION}

Over the past 2 decades, endobronchial ultrasound-guided transbronchial needle aspiration (EBUS-TBNA) has emerged as a minimally invasive, highly accurate technique for sampling the mediastinal lymph node (LN) (1,2). This technique allows for both visualization of the target lesion and the surrounding structures, and the simultaneous collection of a cytological sample of the target lesion under direct sonographic guidance. Since tissue diagnosis is strongly recommended as part of patient management, and because the qualification of the cytological material affects the pathological conclusion, the method of acquiring and processing the EBUS-TBNA specimen plays a critical role in case of a patient with enlarged mediastinal LNs (3).

Recently, with the introduction of novel targeted therapies for non-small cell lung carcinoma (NSCLC), the accurate diagnosis and appropriate classification of subtypes have

(Turk Patoloji Derg 2019, 35:198-206)

Received : 23.10.2018 Accepted : 06.02.2019 become more important in patient management (4). This has led to increased expectations from the pathologist/ cytopathologist, for example, regarding squamous and glandular differentiation, especially in cytological samples. Thus, conventional cytological preparation and cytomorphological evaluation alone do not always provide sufficient information to determine primary or secondary origin of adenocarcinoma, especially in cases of poorly differentiated carcinoma. Other techniques, such as immunohistochemistry (IHC) for subtyping, and molecular analysis for targeted therapies, are often required (5). Consequently, it has become apparent that the means of acquiring and processing the cytological specimens can help to guide optimal treatment of advanced NSCLC (6). The success of EBUS-TBNA, as in fine-needle aspiration (FNA) of other localizations, is directly related to the quality of the sample and the interpretation, and thus, the appropriate treatment of patients. The quality of the sample

Correspondence: Dilek ECE

Dr. Lütfi Kırdar Kartal Eğitim ve Araştırma Hastanesi,

Patoloji Kliniği, İSTANBUL, TURKEY

E-mail: dilekilgiciece@outlook.com Phone: +90 2164413900 / 1055 
is dependent on obtaining and preparing specimens that are representative of the lesion with sufficient quantity and quality for accurate interpretation. However, such criteria defining adequacy and the methodological details about the preparation technique of EBUS-TBNA materials have not yet been clearly determined (7). The daily workload, habits, and the available facilities at each institution affect the processing of specimens. In many centers, the handling of EBUS-TBNA specimens generally consists of conventional smearing and fixation with 95\% alcohol and/or air-drying and additional cell block preparation from the residual material (8-10). In a few centers, liquid-based cytology and/or a combination of these techniques is preferred (11).

As a result of an excessive daily workload at this center, rapid on-site evaluation (ROSE) of FNA and EBUS-TBNA samples is limited. Slide preparations are finalized in an aspiration room by a clinician or other skilled personnel. Traditionally, almost all of the aspiration material is spread onto several slides and there is little residual material for cell block samples. However, the introduction of novel targeted therapies and histological subtyping of NSCLC have increased the cell block importance. In this retrospective study, 2 methods of examining EBUS-TBNA material collected to evaluate mediastinal LNs and lesions from the lung, mediastinum, and trachea were reviewed. The purpose of the study was to compare the sampling adequacy and cell block quality of 2 preparation techniques.

\section{MATERIALS and METHODS}

\section{Population/Patients}

The archives of the institution's pathology and pulmonary disease clinics were reviewed for EBUS-TBNA cases between January 1, 2009 and January 1, 2012, a period of 36 months. The data from a total of 462 specimens of the consecutive 260 patients were assessed. All of the procedure notes and cytological material were retrieved.

\section{EBUS-TBNA Techniques}

Each EBUS-TBNA procedure was performed by a chest physician in the bronchoscopy unit of the pulmonary diseases clinic. A $7.5-\mathrm{MHz}$ BF-UC160F convex probe bronchoscopy (Olympus Optical Co., Tokyo, Japan; approved by FDA) and an EU c2000 processor (Olympus Optical Co., Tokyo, Japan) were used via the oral route. Topical anesthesia was applied with lidocaine, and sedation was administered using midazolam. Aspiration from a target $\mathrm{LN}$ or lesion in the lung, trachea, or mediastinum was executed using an Olympus 22-G NA-201SX-4022-C needle (Olympus Optical Co., Tokyo, Japan; approved by FDA). Rapid on-site evaluation was not performed during the procedure. The number of passes was determined by the chest physician as previously described (12).

\section{Preparation Technique}

Slide preparation was performed in a bronchoscopy suite by a member of the EBUS-TBNA team, a staff pulmonologist, pulmonary resident, or a nurse.

In the first period of the study, almost all of the aspirated material was smeared onto glass slides (2-41 slides per case) and immediately fixed with $95 \%$ alcohol. The remainder of a pass sample was rinsed into a $95 \%$ alcohol-filled tube for cell block preparation. All needles from the same site were rinsed in the same alcohol tube to prepare 1 cell block per site.

In the second period of the study, the EBUS-TBNA team was informed by a pathologist (DE) about alternative processing of the aspirated material in order to improve diagnostic ability. Depending on the quantity of aspirated material, a pair of slides was prepared from each needle pass in this period (1-8 slides per case). For each pair of slides smeared, one was air-dried and the other was fixed immediately in $95 \%$ alcohol. The remnants of aspirate from the same localization were collected in a tube and filled with 95\% alcohol for cell block sampling.

\section{Pathology}

Air-dried slides were stained using May-GrunwaldGiemsa (MGG) stain, and 95\% alcohol-fixed slides with a Papanicolaou stain. Cell blocks were prepared using formalin fixation and paraffin embedding techniques from pellets obtained by centrifugation of the needle rinse fluids. Three- $\mu \mathrm{m}$ slides obtained from cell blocks were stained with hematoxylin and eosin. Immunohistochemical evaluation was performed as needed.

The cytological materials were reassessed for sampling adequacy and cytological diagnosis by a pathologist (DE) with cytopathology experience.

Sampling adequacy was defined as acquisition of tissue sufficient for pathological diagnosis. LN specimens that demonstrated specific diagnoses or adequate lymphocytes were considered adequate. An adequate amount of lymphoid material was defined as the presence of over 40 lymphocytes visible in high power field in the most dense cellular areas of the slides or in the presence of clusters of anthracotic pigment-laden macrophages as defined by Alsharif et al.(8). If no diagnosis was possible or insufficient lymphocytes were available to verify satisfactory LN sampling, the sample was considered inadequate. Aspiration samples of lung, mediastinum, or trachea lesions that demonstrated a specific diagnosis were considered adequate. If no specific diagnosis was made, the sample was considered inadequate, even if bronchial epithelium or pigmented macrophages were found. 
In both LN and lesion specimens, the cytological diagnosis was malignant, atypical, benign, or non-diagnostic. The presence of obviously malignant cells led to a classification in the malignant category. The observation of rare cells that were suspicious but not clearly defined as malignant was considered atypical.

In LN specimens, the presence of adequate lymphocytes without evidence of a tumor was considered benign. Benign diagnoses were categorized as metastasis-negative or granulomatous inflammation.

Lung, mediastinum, and trachea specimens that demonstrated a specific benign lesion, such as granulomatous inflammation, were considered benign.

For both LN and lesion specimens, the sample was determined to be non-diagnostic when there was inadequate material and only blood, mucus and/or necrotic material was seen, or when the specimen was acellular.

Cell blocks containing cells of a specific lesion (tumor or granuloma) were assessed as adequate. These cell blocks were examined with a high-power field, and tumor cells and epithelioid histiocytes were enumerated. The cell count was estimated with a scoring system of 1-4. A sample with a small number of cells was assigned a score of $0(<10$ tumor cells/epithelioid histiocytes), a low cell count merited a score of 1 (approximately 10-49 tumor cells/epithelioid histiocytes), low to moderate numbers were given a score of 2 (approximately 50-99 tumor cells/epithelioid histiocytes), a moderate cell count scored 3 (approximately 100-499 tumor cells/epithelioid histiocytes), and a profuse sample was given a score of 4 (approximately $>500$ tumor cells/epithelioid histiocytes). A cell score of 0 was considered inadequate. Cell blocks that demonstrated a specific diagnosis and were given a cell score of 1 or more were assessed as adequate for IHC evaluation.

Molecular testing at this institution is performed based on clinician request and these data were not reviewed for the current study.

\section{Statistical Analysis}

Diagnostic yield and sampling adequacy were calculated using the standard definitions as described by Ost et al. (13). Diagnostic yield was defined as the frequency of a recognized disease (e.g., NSCLC or granulomatous diseases) on the basis of cytological findings. If, in spite of an adequate number of lymphocytes, no diagnosis was made, the specimen was considered non-diagnostic. These samples were examined and classified for each patient. Sampling adequacy was defined as cytological specimens that demonstrated a specific diagnosis or adequate lymphocytes. If no diagnosis was made or insufficient lymphocytes were available to verify adequate LN sampling, the samples were considered inadequate. These were performed on a per LN/lesion basis.

The data were summarized as the mean $( \pm \mathrm{SD})$, and median (range) for continuous variables and as a percentage for categorical variables. Normal distribution was tested with the Kolmogorov-Smirnov test. The Pearson chi-square test was used to test categorical variables and Student's t-test for continuous variables. A $p$ value of $<0.05$ was considered significant for all tests. IBM SPSS Statistics for Windows, Version 20.0 (IBM Inc., Armonk, NY, USA) was used to perform the analysis.

\section{RESULTS}

In all, 462 EBUS-TBNA specimens obtained from 260 patients [158 males (60.8\%), 102 females (39.2\%)] were included in the study. The patients' age ranged from 16 to 82 years, with a median age of 55 years. From the total of 260 patients, 177 specimens were sampled from 114 patients during the first period and 285 specimens from 146 patients were analyzed in the second period. The data of patient and sample characteristics are summarized in Table I. There was no statistically significant differentiation in the demographics of the patients from the first and second periods of the study.

\section{Specimen Texting}

The mean number of slides per LN station/lesion sampled was greater in the first period group than the second (12.8 vs $3.9 ; \mathrm{p}<0.001)$.

There were a great many more cell blocks prepared from EBUS-TBNA aspirate in the second period group compared with the first $(33.9 \%$ vs $97.9 \%$; $<<0.001)$. An adequate quantity of cells for additional evaluation was available in $14.1 \%$ and $42.1 \%$ of the samples in the first and second period, respectively ( $\mathrm{p}<0.001)$ (Table II).

The cytological diagnoses of the specimens are summarized in Table III. Of the benign cytological samples, $24.9 \%$ $(44 / 177)$ in the first period and $28.1 \%(80 / 285)$ in the second period revealed granulomatous inflammation (Figure 1A-D). The overall sampling adequacy of EBUSTBNA specimens was $78.4 \%$ on a per LN/lesion basis. In the first group, the sampling adequacy was $74 \%$ compared with $81.1 \%$ in the second group. The difference was statistically significant $(\mathrm{p}<0.05)$.

\section{Patient Characteristics}

A specific diagnosis was made in 148 (56.9\%) patients. The diagnostic yields were $54.4 \%$ and $58.9 \%$ in the first and second period, respectively. The difference was statistically insignificant $(\mathrm{p}=0.27)$. 
Of the total of 260 patients, 78 [30 (26.3\%) and 48 (32.9\%) in the first and second period, respectively] had granulomatous inflammation, and $70[32(28.1 \%)$ and $38(26 \%)$ in the first and second period, respectively] demonstrated a malignancy $(\mathrm{p}=0.741)$.

\section{Immunohistochemistry and Subtyping of Tumors}

The IHC method was used for the histological subtyping of tumors in patients with a malignancy. IHC techniques were used to evaluate cell blocks in $18.8 \%$ (6 patients) in the first period, compared with $35.6 \%$ (21 patients) in the second period. The histological subtyping of tumors, established based on morphological and IHC characteristics, are illustrated in Table IV. The extrapulmonary malignancies determined were breast carcinoma $(n=1)$ and renal cell carcinoma $(\mathrm{n}=1)$ in the first period, and colorectal carcinoma $(n=1)$, breast carcinoma $(n=2)$, and malignant melanoma $(\mathrm{n}=1)$ in the second period (Figures $2 A-D, 3 A-D)$.

Table I: Patient and specimen characteristics.

\begin{tabular}{lccc}
\hline Variable & First period $\mathbf{( n = 1 1 4} \mathbf{p} ; \mathbf{1 7 7} \mathbf{s p})$ & Second period (n=146 p; 285 sp) & P value \\
\hline Age (years) & $53.4 \pm 13.69$ & $53.3 \pm 13.97$ & 0.819 \\
\hline Gender (M/F) & $67 / 47(59 / 41 \%)$ & $91 / 55(62 / 38 \%)$ & 0.324 \\
\hline LN/lesion size* & $1.89 \pm 1.02$ & $2.05 \pm 1.1$ & 0.507 \\
\hline Number of passes & $1.78 \pm 0.69$ & $1.97 \pm 0.68$ & 0.013 \\
\hline Number of slides & $12.81 \pm 6.65$ & $3.9 \pm 1.54$ & $<0.001$ \\
\hline Sampling localization & & & \\
2R & $4(2.3 \%)$ & $3(1.1 \%)$ & 0.151 \\
3 & $0(0 \%)$ & $3(1.1 \%)$ & \\
$4 \mathrm{~L}$ & $8(4.5 \%)$ & $17(6 \%)$ & \\
$4 \mathrm{R}$ & $41(23.2)$ & $77(27 \%)$ & \\
7 & $72(40.7 \%)$ & $100(35.1 \%)$ & \\
10L & $2(1.1 \%)$ & $3(1.1 \%)$ & \\
10R & $9(5.1 \%)$ & $12(4.2 \%)$ & \\
11L & $22(12.4 \%)$ & $19(6.7 \%)$ & \\
11R & $16(9 \%)$ & $39(13.7 \%)$ & \\
Lesion & $3(1.7 \%)$ & $12(4.2 \%)$ & \\
\hline
\end{tabular}

*short axis diameter. F: Female; LN: Lymph node; M: Male; P: Patients; Sp: Specimen.

Data are presented as mean \pm SD. P values calculated using a chi-square test for categorical variables and Student's t-test for continuous variables.

Table II: Semi-quantitative assessment of cell blocks.

\begin{tabular}{lccc}
\hline Cell quantity & First period & Second period & P value \\
\hline $10-49$ cells & $12(6.8 \%)$ & $48(16.8 \%)$ & \\
\hline $50-99$ cells & $8(4.5 \%)$ & $22(7.7 \%)$ & $<0.001$ \\
\hline $100-499$ cells & $2(1.1 \%)$ & $25(8.8 \%)$ & \\
\hline 500 cells or more & $3(1.7 \%)$ & $25(8.8 \%)$ & \\
\hline Unsatisfactory/unprepared & $152(85.9 \%)$ & $165(57.9 \%)$ & \\
\hline Total & $177(100 \%)$ & $285(100 \%)$ & \\
\hline
\end{tabular}

Table III: Diagnosis of specimens.

\begin{tabular}{lccc}
\hline Diagnosis & First period & Second period & P value \\
\hline Malignant & $39(22 \%)$ & $59(20.7 \%)$ & \\
\hline Benign & $86(48.6 \%)$ & $163(57.2 \%)$ & \\
\hline Atypical cytological findings & $6(3.4 \%)$ & $9(3.2 \%)$ & 0.307 \\
\hline Non-diagnostic & $46(26 \%)$ & $54(18.9 \%)$ & \\
\hline Total & $177(100 \%)$ & $285(100 \%)$ & \\
\hline
\end{tabular}


Table IV: Histological subtypes of tumors in 70 patients.

\begin{tabular}{lcc}
\hline Tumor type & First period & Second period \\
\hline Non-small cell lung carcinoma (NOS) & \multirow{2}{*}{ ( } & $3(7.9 \%)$ \\
\hline Squamous cell carcinoma & $9(28.1 \%)$ & $10(26.4 \%)$ \\
\hline Adenocarcinoma & $4(12.5 \%)$ & $12(31.6 \%)$ \\
\hline Large cell neuroendocrine carcinoma & $0(0 \%)$ & $1(2.6 \%)$ \\
\hline Small cell carcinoma & $3(9.4 \%)$ & $5(13.2 \%)$ \\
\hline Poorly differentiated carcinoma & $1 *$ & $1(2.6 \%)$ \\
\hline Extrapulmonary malignancy & $2(6.1 \%)$ & $4(10.5 \%)$ \\
\hline Adenocarcinoma (pulmonary/extrapulmonary) & $1(3.1 \%)$ & $1(2.6 \%)$ \\
\hline Undifferentiated tumor & $0(0 \%)$ & $1(2.6 \%)$ \\
\hline Total & $32(100 \%)$ & $38(100 \%)$ \\
\hline
\end{tabular}

* NOS: Not otherwise specified, ${ }^{\star *}$ Small cell carcinoma/non-small cell lung carcinoma.
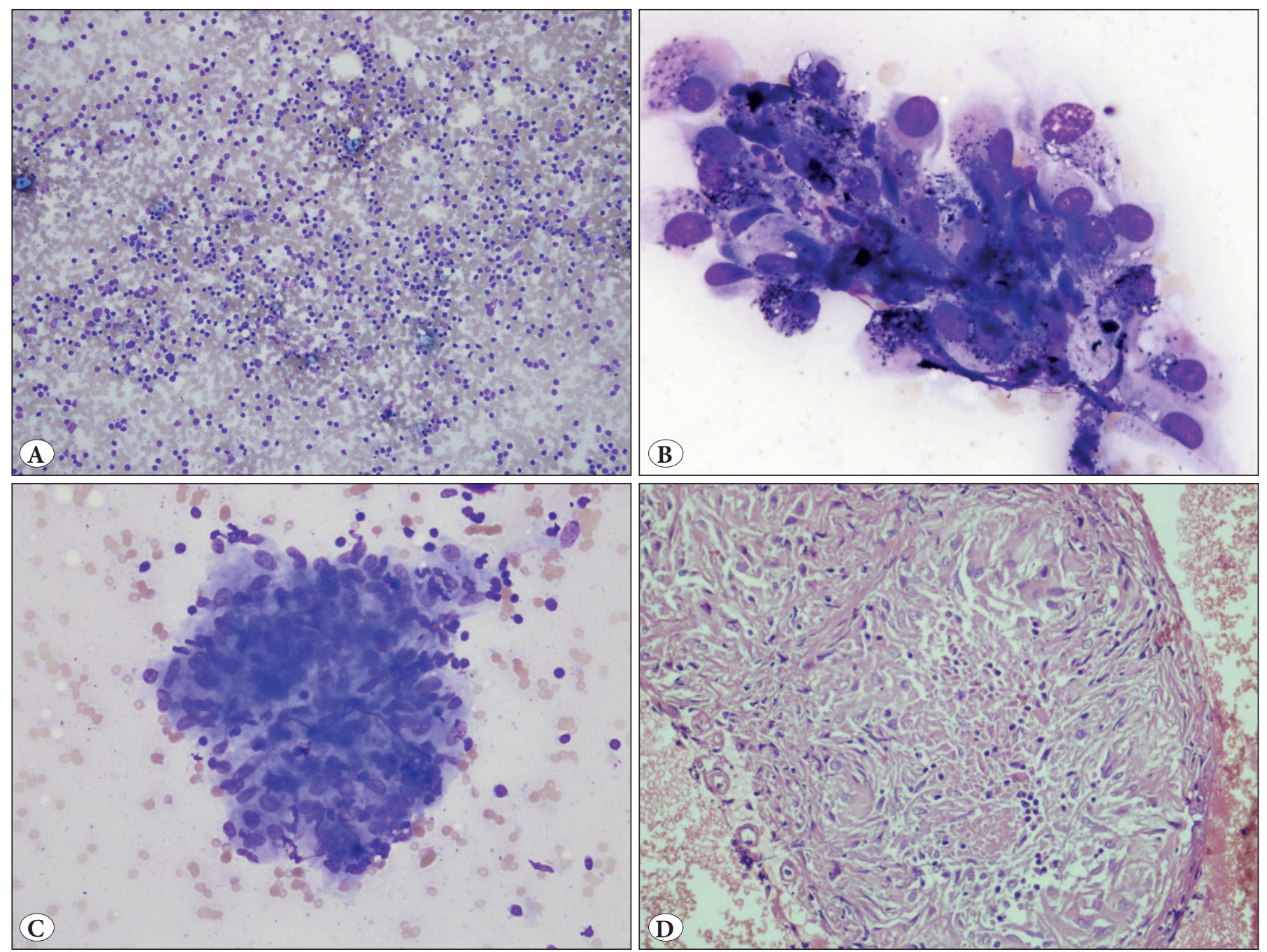

Figure 1: Benign cytological samples. A,B) Benign adequate lymph node. A) Over 40 lymphocytes seen in high power field in the most dense areas of the slide (MGG; x100). B) Pigmented macrophages (MGG; x1000). C,D) Granulomatous inflammation. C) Epithelioid histiocytes (MGG; x200). D) Granuloma with necrosis in cell block (H\&E; x200). 

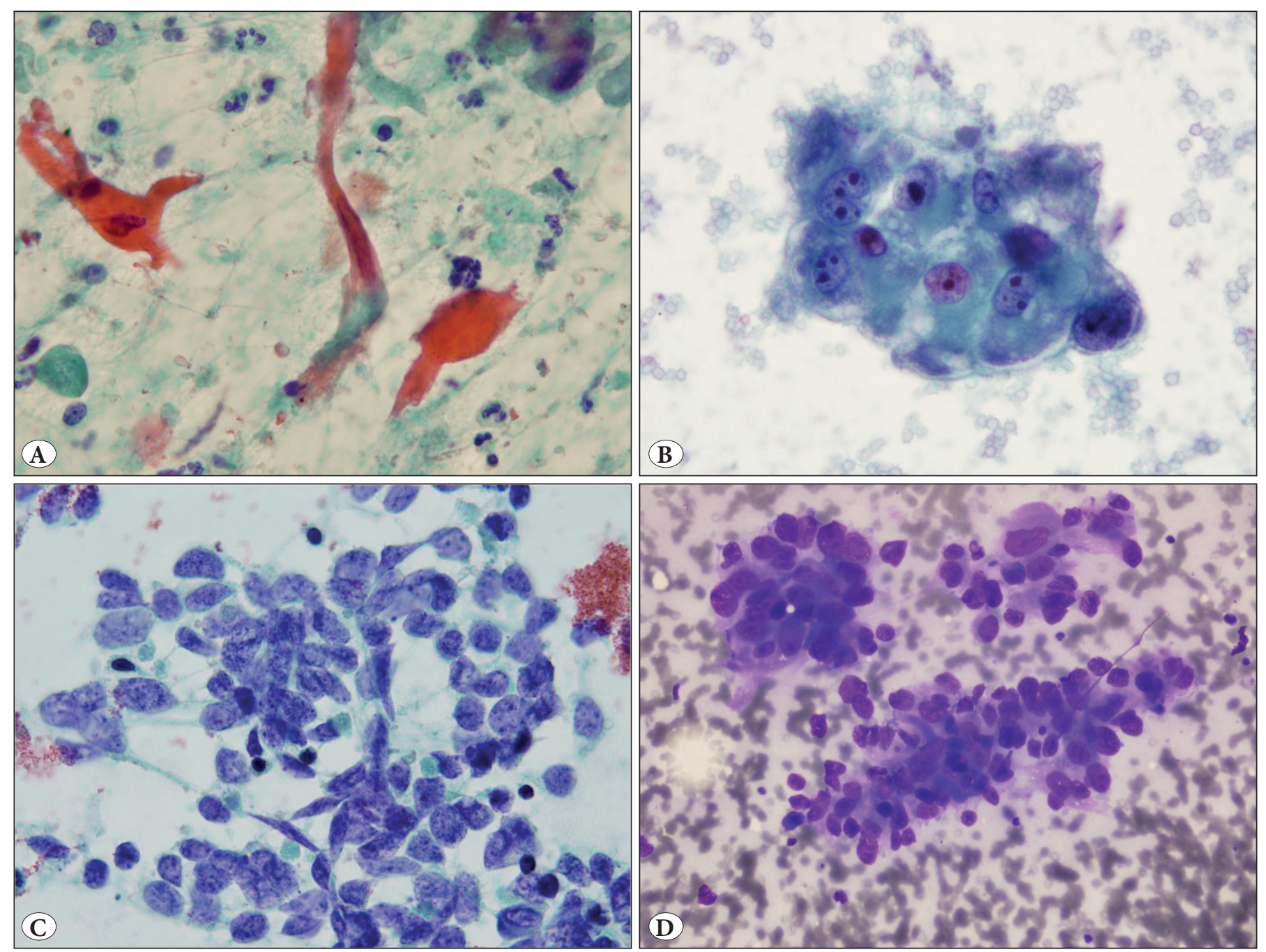

Figure 2: Cytological features of lung carcinomas. A) Squamous cell carcinoma (PAP; x400). B) Adenocarcinoma (PAP; x400). C) Small cell carcinoma (PAP; x1000). D) Large cell neu-roendocrine carcinoma (MGG; x400).

\section{DISCUSSION}

Although, sampling adequacy is an important component of EBUS-TBNA performance, the criteria for adequacy have not yet been established (7). Similarly, the methodological detail of the preparation technique is not clear. Studies have revealed a variation in the acceptability rate of EBUS-TBNA samples $(8,9,11,14)$. Due to the fact that EBUS-TBNA is a multistep process, many factors (number of needle passes, needle size, type of sedation, aspirator experience, aspiration localization, LN size, and the use of ROSE) have the potential to affect the adequacy of the specimen (1121). Hence, factors influencing EBUS-TBNA sampling adequacy have been the subject of many studies. Most of these factors, including anesthesia type, needle size, the EBUS-TBNA team, and the cytopathologist, were the same and ROSE was not performed during our 2 study periods.
Statistically, the number of needle passes, the LN/lesion size, and the aspiration localization were not significantly different between procedure periods. Only the preparation technique was different in the first and the second periods of this study. We focused on the relationship between preparation technique and sampling adequacy and cell block quality in this study.

The majority of EBUS-TBNA studies, as in our second period, have used both wet-fixation with 95\% alcohol and an air-drying technique with cell block evaluation prepared from the residual material. The adequate diagnostic specimen rates have been reported at between $94 \%$ and $77 \%$ (8-12). Specimen adequacy was observed in $81.1 \%$ in the second period of our study. In the first period, in which only wet fixation with $95 \%$ alcohol was used, it was $74 \%$. Nonetheless, in 1 study that used only wet fixation, 

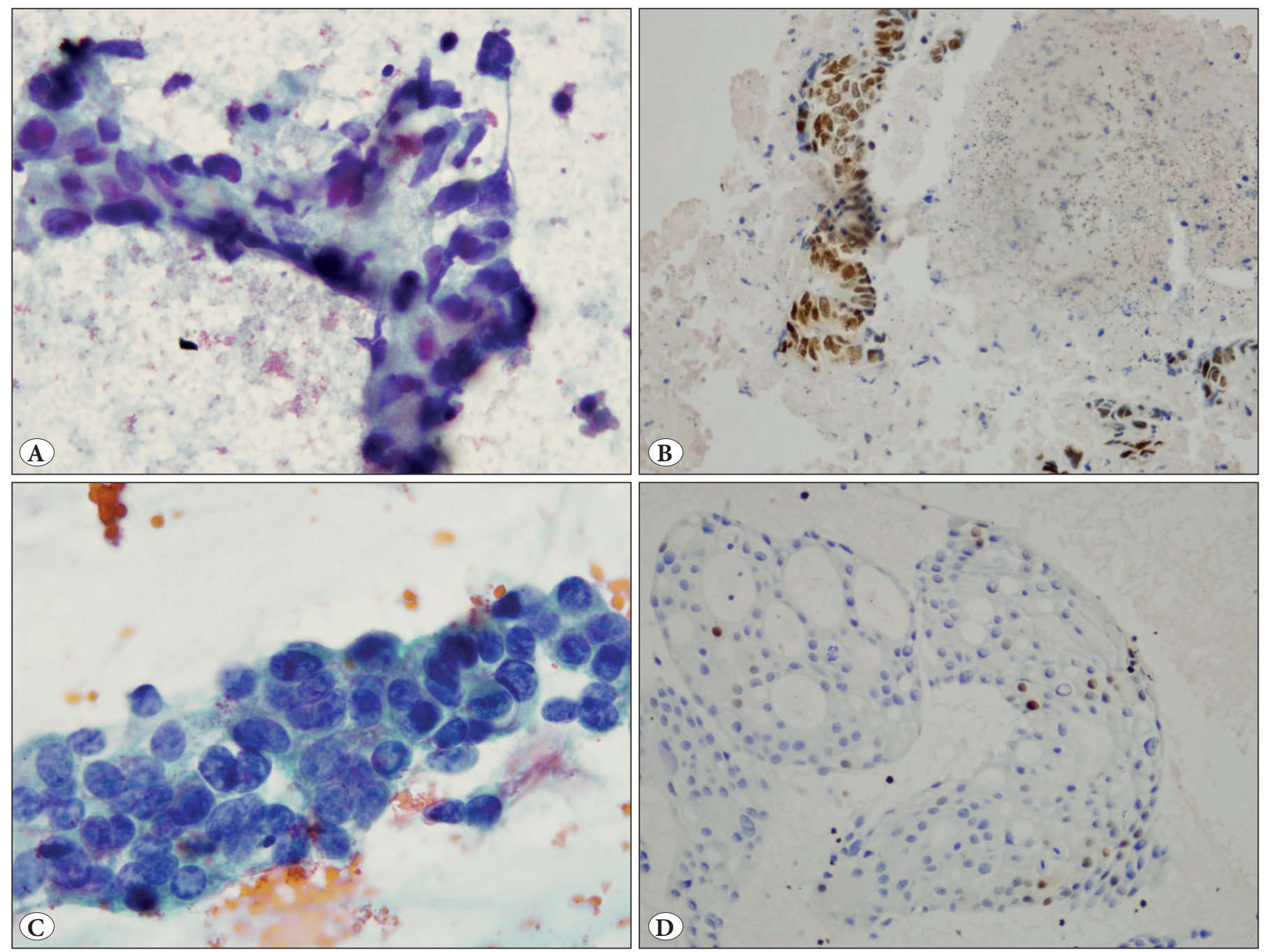

Figure 3: Cytological features of extrapulmonary metastases. A,B) Colon carcinoma. A) (PAP; x1000). B) Immunohistochemistry with CDX2 (IHC; x100). C,D) Breast carcinoma. C) (PAP; x1000). D) Immunohistochemistry with estrogen receptor (IHC; x200).

the adequate specimen rate was reported as $92 \%$ (15). The technique of the aspiration provides specimen adequacy. Each pass in the study provided qualified and abundant material, including tissue cores. A lower adequacy rate in the first period of our study may be related to spreading most of the material on slides, rather than using the fixation method.

Various slide results have been reported in EBUS-TBNA studies. Some have described smearing slides for each aspiration, and others per aspiration site or per case (811,15). In Alsharif's study, (8) with a mean of 6 slides prepared for each LN localization, independent of the LN station, the specimen adequacy rate was $84.3 \%$. Similarly, in the second period of our study, a mean of 4 slides was prepared for each aspiration localization, and the adequacy rate was found to be $81.1 \%$, independent of the aspiration site. In the first period, however, the average was 13 slides prepared for each localization and the adequacy rate was $74 \%$.

Although the difference in diagnostic yield was not significant between the first and second periods of the study, the difference in adequacy rate was statistically significant.

The cell blocks of EBUS-TBNA material from the second period displayed substantially more cells. Smearing the majority of the aspirated material on slides may lead to too little material remaining for an ancillary cell block technique. Neoplastic cells may be identified on slides, but histological subtyping of a tumor may not be determined.

A converse habit for the preparation of slides, using just a portion of the aspirated material, may provide both neoplastic cells on slides and more material for an ancillary cell block technique. 
Recently it has become apparent that subtyping and genotyping help to guide optimal treatment of advanced NSCLC. The pathologist/cytopathologist has had to cope with a rise in the need for accurate diagnosis and appropriate classification of subtypes. It's well known that adenocarcinomas and squamous cell carcinomas can be diagnosed in most instances, especially with the aid of cell blocks and IHC in cases of poorly differentiated carcinomas (5). Consequently, cell block preparation from EBUS-TBNA samples is a simple way to provide additional information in cases of NSCLC. Sanz-Santos et al. (22) investigated the contribution of cell blocks to the diagnosis of lung cancer and found that $47.9 \%$ of EBUS-TBNA specimen cell blocks from EBUS-TBNA sampling provided additional important information. Adequate material for diagnosis was recovered from $37.6 \%$ of the samples. Cell block processing provided clinically significant information for one-third of the lung cancer patients in their study. Histological subtyping of NSCLC and the primary origin of tumors was determined using morphological and IHC properties in $18(56.3 \%)$ patients in the first period and 33 $(86.8 \%)$ patients in the second period of our study.

In addition to the histological subtyping of NSCLC, molecular testing to identify key driver mutations is required for the appropriate treatment of patients with adenocarcinoma. These ancillary tests require an adequate amount of tissue. Molecular tests, such as EGFR mutation, KRAS mutation, and ALK gene rearrangement analyses can be reliably performed on cell block material from cytological specimens $(5,22)$. Successful EGFR DNA sequence analysis can be obtained from as few as 30 to 100 tumor cells (23). In our study, cell blocks contained a minimum of 50 tumor cells in 9 (23.1\%) of 39 malignant cases in the first period and 30 (50.9\%) of 59 malignant cases in the second period.

As demonstrated in the second period of our study, leaving a little more material aside for cell block analysis instead of smearing the majority of the material from a EBUSTBNA specimen on slides will provide the opportunity for morphological diagnosis, IHC, and molecular analysis in order to provide the appropriate treatment.

Limitations of this study include the small sample size and the lack of molecular analysis results. However, the reliability of the results is increased due to the single-center approach and focus on preparation technique.

In conclusion, recent advances in therapy for NSCLC and concurrent developments in EBUS-TBNA have allowed for a combined use of EBUS-TBNA for tissue acquisition and genotyping of lung carcinoma. Sufficient material and appropriate preparation, especially high-quality cell block preparations, can affect the diagnosis, staging, and treatment of a patient with a single procedure.

\section{CONFLICT of INTEREST}

The authors declare no conflict of interest.

\section{REFERENCES}

1. Krasnik M, Vilmann P, Larsen SS, Jacobsen GK. Preliminary experience with a new method of endoscopic transbronchial real time ultrasound guided biopsy for diagnosis of mediastinal and hilar lesions. Thorax. 2003;58:1083-6.

2. Chandra S, Nehra M, M, Agarwal D, Mohan A. Diagnostic accuracy of endobronchial ultrasound-guided transbronchial needle biopsy in mediastinal lymphadenopathy: A systematic review and meta-analysis. Respir Care. 2012;57:384-91.

3. De Leyn P, Dooms C, Kuzdzal J, Lardinois D, Passlick B, RamiPorta R, Turna A, Van Schil P, Venuta F, Waller D, Weder W, Zielinski M. Revised ESTS guidelines for preoperative mediastinal lymph node staging for non-small-cell lung cancer. Eur J Cardiothorac Surg. 2014;45:787-98.

4. Rossi G, Pelosi G, Graziano P, Barbareschi M, Papotti M. A reevaluation of the clinical significance of histological subtyping of non-small-cell lung carcinoma: Diagnostic algorithms in the era of personalized treatments. Int J Surg Pathol. 2009;17:206-18.

5. Nicholson AG, Gonzalez D, Shah P, Pynegar MJ, Deshmukh M, Rice A, Popat S. Refining the diagnosis and EGFR status of nonsmall cell lung carcinoma in biopsy and cytologic material, using a panel of mucin staining, TTF-1, cytokeratin 5/6, and P63, and EGFR mutation analysis. J Thorac Oncol. 2010;5:436-41.

6. Bulman W, Saqi A, Powell CA. Acquisition and processing of endobronchial ultrasound-guided transbronchial needle aspiration specimens in the era of targeted lung cancer chemotherapy. Am J Respir Crit Care Med. 2012;185:606-11.

7. Skov BG, Baandrup U, Jakobsen GK, Kiss K, Krasnik M, Rossen K, Vilmann P. Cytopathologic diagnoses of fine-needle aspirations from endoscopic ultrasound of the mediastinum: Reproducibility of the diagnoses and representativeness of aspirates from lymph nodes. Cancer. 2007;111:234-41.

8. Alsharif M, Andrade RS, Groth SS, Stelow EB, Pambuccian SE. Endobronchial ultrasound-guided transbronchial fine-needle aspiration: The University of Minnesota experience, with emphasis on usefulness, adequacy assessment, and diagnostic difficulties. Am J Clin Pathol. 2008;130:434-43.

9. Jacob-Ampuero MP, Haas AR, Ciocca V, Bibbo M. Cytologic accuracy of samples obtained by endobronchial ultrasoundguided transbronchial needle aspiration at Thomas Jefferson University Hospital. Acta Cytol. 2008;52:687-90.

10. Feller-Kopman D, Yung RC, Burroughs F, Li QK. Cytology of endobronchial ultrasound-guided transbronchial needle aspiration: A retrospective study with histology correlation. Cancer. 2009;117:482-90.

11. Griffin AC, Schwartz LE, Baloch ZW. Utility of on-site evaluation of endobronchial ultrasound-guided transbronchial needle aspiration specimens. Cytojournal. 2011;8:20. 
12. Ece D, Keser SH, Çağlayan B, Salepçi B, Güler GB, Sensu S, Geçmen G, Kökten Ş. Endobronchial ultrasound-guided transbronchial fine needle aspiration: Determinants of adequacy. Turkish Journal of Thoracic and Cardiovascular Surgery. 2018;26:123-31

13. Ost DE, Ernst A, Lei X, Feller-Kopman D, Eapen GA, Kovitz KL, Herth FJF, Simoff M; AQuIRE Bronchoscopy Registry. Diagnostic yield of endobronchial ultrasound-guided transbronchial needle aspiration: Results of the AQuIRE Bronchoscopy Registry. Chest. 2011;140:1557-66.

14. DePew ZS, Edell ES, Midthun DE, Mullon JJ, Bungum AO, Decker PA, Maldonado F; Mayo Pulmonary Procedural Group. Endobronchial ultrasound-guided transbronchial needle aspiration: Determinants of sampling adequacy. J Bronchology Interv Pulmonol. 2012;19:271-6.

15. Lee HS, Lee GK, Lee HS, Kim MS, Lee JM, Kim HY, Nam BH, Zo JI, Hwangbo B. Real-time endobronchial ultrasound-guided transbronchial needle aspiration in mediastinal staging of nonsmall cell lung cancer: How many aspirations per target lymph node station? Chest. 2008;134:368-74.

16. Yarmus LB, Akulian J, Lechtzin N, Yasin F, Kamdar B, Ernst A, Ost DE, Ray C, Greenhill SR, Jimenez CA, Filner J, FellerKopman D; American College of Chest Physicians Quality Improvement Registry, Education, and Evaluation (AQuIRE) Participants. Comparison of 21-gauge and 22-gauge aspiration needle in endobronchial ultrasound-guided transbronchial needle aspiration: Results of the American College of Chest Physicians Quality Improvement Registry, Education, and Evaluation Registry. Chest. 2013;143:1036-43.
17. Yarmus LB, Akulian JA, Gilbert C, Mathai SC, Sathiyamoorthy S, Sahetya S, Harris K, Gillespie C, Haas A, Feller-Kopman D, Sterman D, Lee HJ. Comparison of moderate versus deep sedation for endobronchial ultrasound transbronchial needle aspiration. Ann Am Thorac Soc. 2013;10:121-6.

18. Groth SS, Whitson BA, D'Cunha J, Maddaus MA, Alsharif M, Andrade RS. Endobronchial ultrasound-guided fine-needle aspiration of mediastinal lymph nodes: A single institution's early learning curve. Ann Thorac Surg. 2008;86:1104-9;1109-10.

19. Jhun BW, Park HY, Jeon K, Koh WJ, Suh GY, Chung MP, Kim H, Kwon OJ, Han J, Um SW. Nodal stations and diagnostic performances of endobronchial ultrasound-guided transbronchial needle aspiration in patients with non-small cell lung cancer. J Korean Med Sci. 2012;27:46-51.

20. Herth F, Becker HD, Ernst A. Conventional vs endobronchial ultrasound-guided transbronchial needle aspiration: A randomized trial. Chest. 2004;125:322-5.

21. Kennedy MP, Jimenez CA, Morice RC, Sarkiss M, Lei X, Rice D, Eapen GA. Factors influencing the diagnostic yield of endobronchial ultrasound-guided transbronchial needle aspiration. J Bronchology Interv Pulmonol. 2010;17:202-8.

22. Sanz-Santos J, Serra P, Andreo F, Llatjós M, Castellà E, Monsó E. Contribution of cell blocks obtained through endobronchial ultrasound-guided transbronchial needle aspiration to the diagnosis of lung cancer. BMC Cancer. 2012;12:34.

23. da Cunha Santos G, Saieg MA. Preanalytic parameters in epidermal growth factor receptor mutation testing for nonsmall cell lung carcinoma: A review of cytologic series. Cancer Cytopathol. 2015;123:633-43. 